\title{
Research on X Company Supplier Selection Problem
}

\author{
Hongqi Hui \\ School of Economics and Management \\ Hebei University of Science and Technology \\ Shijiazhuang, China
}

\author{
Hongli Guo \\ School of Economics and Management \\ Hebei University of Science and Technology \\ Shijiazhuang, China
}

\begin{abstract}
As the domestic logistics industry continues to grow and develop, higher levels of integration and optimization of the supply chain enter the management of the enterprise, thereby enhancing the competitiveness of the enterprise in society. As an indispensable part of the supply chain, suppliers affect the real profit of the company and affect the long-term strategic development of the company. Therefore, it is necessary to attach great importance to the supplier selection problem. The choice of traditional suppliers mainly focuses on the quality and price of products. In addition to the quality and price of products, the choice of suppliers in the supply chain environment also pays attention to the comprehensive capabilities of suppliers' operational qualifications, corporate environment and product research and development capabilities. The long-term stable strategic partnership is more suitable for the requirements of supplier selection standards under the new situation. This article uses $X$ company as an example to use the gray correlation analysis method $X$ company's suppliers to select the best supplier.
\end{abstract} select

Keywords-supplier; supply chain; Grey correlation analysis;

\section{INTRODUCTION}

\section{A. Research Background And Significance}

As the national economic growth gradually slows down, the economy of various industries gradually declines, and the overcapacity of home appliance enterprises is an indisputable fact. With the substantial reduction of orders, the speed of production of the company has also slowed down, unable to afford warehousing and labor. The cost of suppliers and the supply of suppliers are gradually decreasing. Home appliance companies are in trouble. In order to survive in the market and develop for a long time, small household electrical appliance enterprises must reduce production costs, shorten production cycle, improve product quality and service quality. To enhance market competitiveness. These rely on the enterprise itself can not be achieved, we must choose better suppliers to work together to solve production and cost problems, and ultimately achieve a win-win situation for small household appliances companies and suppliers.

This article takes $\mathrm{X}$ small household electrical appliance company as an example. The supplier of X company still stays in the traditional mode of supplier selection. At the current stage, the supplier's choice in the supply chain environment is not only concerned with product quality and price, but also pays attention to supply. The company's operational qualifications, corporate environment, product research and development capabilities and other comprehensive capabilities to form a long-term stable strategic partnership, more suitable for the new situation and low-cost environment requirements for supplier selection standards.

\section{B. Review of related research}

With the economic development of the society, the choice of suppliers of production enterprises is more and more important, and the response to the supply chain is fast. At present, the research on supplier management at home and abroad is gradually matured, focusing on supplier evaluation and selection, supply cost management, Supplier material source. It is mainly verified by constructing a mathematical model by proposing the corresponding theory. This paper collects and collates relevant literatures such as supplier selection, supplier performance management, and reviews relevant literature.

Zhang Zhe [1], focusing on exploring a universal innovation path for the supplier-managed system approach to process material manufacturing companies to improve supplier management issues.

Zhao Jianfeng [2], pointed out that most of the L company procurement engineers have insufficient experience in supplier selection, and the business level is lacking. To improve these deficiencies, it takes time for them to practice and summarize.

$\mathrm{Xu}$ Jie Zhang [3], Lanting, based on the gray correlation analysis of China's marine fishery industry structure, analyzes China's marine fishery industry structure, and puts forward corresponding suggestions for the development of China's marine fishery economy, the promotion of marine fishery resources development and utilization and the optimization and upgrading of fishery industry structure.

$\mathrm{Yu}$ Yingying [4], in view of the problems existing in the management of suppliers in the procurement process of Chinese enterprises at present, mainly analyzes and discusses the win-win relationship between enterprise procurement activities and suppliers, aiming to better promote the development of Chinese enterprises and progress.

Zhang Yanfeng[5], said that it is impossible to achieve relying solely on the management of the enterprise itself. Small household electrical appliance enterprises must choose excellent suppliers to work together to achieve a win-win situation or even a win-win situation. 


\section{RELATED THEORY}

\section{A. Supplier-Selected Metrics}

Supplier selection issues should be considered in many ways and in many factors. The choice of suppliers is affected by many factors such as natural environment, production capacity, product quality, and supply. It is necessary to select indicators that are easy to measure and convenient to collect data for evaluation. In the decision-making of suppliers, it is necessary to comprehensively consider the nine factors such as product quality, product price, after-sales service, geographical location, technical level, supply capacity, economic benefit, delivery status and market influence. The specific requirements of each factor are as follows.

a) Product quality refers to the degree to which the supplier's products meet the needs of the enterprise. Product quality is expressed by product qualification rate

Product qualification rate $=$ (number of qualified products / total number of products $) \times 100 \%$

b) Product price refers to the cost of purchasing each unit of product, which is an important factor.

c) The level of after-sales service is an important indicator when selecting suppliers. The so-called problem resolution time is a period of time when the user asks a question and the problem is solved satisfactorily.

d) Geographic location is the distance between the supplier's location and the location of the business. Suppliers with close proximity are beneficial to management.

e) The technical level refers to whether the technical parameters of the goods provided by the supplier meet the requirements. It is beneficial to select the suppliers with hightech standards for the long-term development of the enterprise.

f) Supply capacity refers to the supplier's production capacity and is able to guarantee the quantity of products required by the customer.

g) Economic efficiency refers to the ability of suppliers to make profits. Here, the return on equity is used to represent economic benefits:

Net assets income $=($ total profit $/$ total net assets $) \times 100 \%$

h) The delivery status refers to the supplier's timely meeting of the enterprise order level. Here, the delivery rate is expressed by the on-time delivery rate:

On-time delivery rate $=($ batch delivered by batch/order confirmed on time) $\times 100 \%$

i) Market influence refers to the sales of products provided by suppliers in the market. We use market share to express market influence:

Market share $=$ (number of suppliers / number of similar products in the market) $\times 100 \%$

In the above expression, the product quality, technical level supply capacity, economic benefit, delivery status, and market influence index are larger and better, which is a benefit indicator; product price, after-sales service, and geographical location indicators are smaller and better, belonging to cost. Type indicator

\section{B. The basic idea of grey relational analysis}

The degree of correlation between the comparison sequence and the reference sequence is determined according to the degree of geometric similarity between the curve formed by each comparison sequence and the reference sequence. The closer the geometry is, the greater the degree of association. In the supplier selection decision, each candidate supplier can be used as a comparison series, and the optimal supplier is used as a reference series.

Set to represent the first supplier, indicating the best supplier, and

$$
\begin{gathered}
x_{i}=\left\{x_{i}(k) \mid k=1,2, \ldots, n\right\}(i=1,2, \ldots, m) \\
x_{0}=\left\{x_{0}(k) \mid k=1,2, \ldots, n\right)
\end{gathered}
$$

Trial: The number of suppliers to be selected; the number of indicators, that is, the number of factors selected by the supplier; the original value of the first indicator of the first supplier.

Since there is a dimensional difference between the indicators, there is no operational relationship between the data, so it is necessary to generate and process these raw data and convert them into numbers in the interval $[0,1]$. The following two formulas can be used to generate data:

$$
\begin{aligned}
& x_{i}(k)=\frac{x_{i}(k)-\min x_{i}(k)}{\max x_{i}(k)-\min x_{i}(k)} i=1,2, \ldots, m ; k=1,2, \ldots n \\
& x_{i}(k)=\frac{\max x_{i}(k)-x_{i}(k)}{\max x_{i}(k)-\min x_{i}(k)} i=1,2, \ldots, m ; k=1,2, \ldots n
\end{aligned}
$$

Trial: Indicates the minimum and maximum values of the first indicator in the plan; the former applies to the benefit indicator set, and the minimum value of the indicator in the supplier evaluation index; the latter applies to the cost indicator set, and the indicator is evaluated in the supplier. The maximum value in the indicator.

After the original data is processed by the interval, the correlation coefficient can be calculated by pressing:

$$
\begin{gathered}
\text { Assume: } \Delta_{i}(k)=\left|x_{0}(k)-x_{i}(k)\right| \\
\xi_{i}(k)=\frac{\min \min \Delta_{i}(k)+\xi \max \max \Delta_{i}(k)}{\Delta_{i}(k)+\xi \max \max \Delta_{i}(k)}
\end{gathered}
$$

Trial: Indicates the absolute difference from the first indicator: indicates the correlation coefficient with the indicator at the first indicator, which is the resolution coefficient. The role in the equation is very important, it can not only adjust the size, but also control the change interval of the correlation coefficient. The usual range of values is in the $[0,1]$ range, which is based on experience and has a value of 0.5. And represent the minimum absolute difference and the maximum absolute difference, respectively. 
The correlation coefficient has a large number of values, and the information is too scattered, which is not convenient for comparison. In order to make the information relatively concentrated, the correlation coefficient can be averaged, and the correlation degree is calculated as follows:

$$
r_{i}=\frac{1}{n} \sum_{k=1}^{n} \xi_{i}(k)
$$

Where: indicates the degree of association with and; when in the interval $(0,1)$, it means that any factor in the system is not strictly irrelevant. If it is larger, it means that the closer the supplier is to the optimal supplier, that is, the first supplier is better than the other suppliers, so that the order of the various programs can be discharged, which can be used as the decision-making basis for decision makers.

\section{CASE ANALYSIS OF SUPPLIER SELECTION BASED ON GREY CORRELATION ANALYSIS}

\section{A. Basic Situation Of X Company}

$\mathrm{X}$ company is a strong small household appliance manufacturer, the products sell well all over the country and exported to Europe, Australia, India and other countries and regions. Recently, due to overcapacity in the home appliance industry, the company's equipment has been remodeled, and new products have been introduced. This has led to the continuous development of new procurement materials, and there is no supplier of these new materials. X company's supplier selection efficiency has not been high, it is difficult to develop a supplier that suits the market environment and company requirements. The procurement department is often complained by the material demand department and other stakeholders. The company's entire supply chain management is in the supplier. The delivery delay is affected. In order to better occupy the home appliance market, X Company must solve the problem of difficult supply and delay of supply chain. These problems cannot be solved by the company itself. We must find better suppliers to complete together and achieve a win-win situation. This article takes Company A as an example to talk about the problems existing in the selection of suppliers of small household electrical appliances enterprises, and gives solutions. The data for suppliers of $\mathrm{X}$ companies is shown in Table 1.

TABLE I COMPANY'S CANDIDATE SUPPLIERS' EVALUATION OF RELEVANT DATAS

\begin{tabular}{|l|l|l|l|l|l|l|}
\hline Evaluation index & \multicolumn{6}{|l|}{ Pending supplier } \\
\hline & 1 & 2 & 3 & 4 & 5 & 6 \\
\hline 1 product quality & 0.83 & 0.90 & 0.99 & 0.92 & 0.87 & 0.95 \\
\hline $\begin{array}{l}\text { 2 product price / } \\
\text { yuan }\end{array}$ & 326 & 295 & 340 & 287 & 310 & 303 \\
\hline $\begin{array}{l}\text { 3geographical } \\
\text { location / km }\end{array}$ & 21 & 38 & 25 & 19 & 27 & 10 \\
\hline $\begin{array}{l}\text { 4after sales service } \\
\text { / hour }\end{array}$ & 3.2 & 2.4 & 2.2 & 2.0 & 0.9 & 1.7 \\
\hline 5 technical level & 0.20 & 0.25 & 0.12 & 0.33 & 0.20 & 0.09 \\
\hline 6economic benefits & 0.15 & 0.20 & 0.14 & 0.09 & 0.15 & 0.17 \\
\hline $\begin{array}{l}7 \text { supply capacity / } \\
\text { pieces }\end{array}$ & 250 & 180 & 300 & 200 & 150 & 175 \\
\hline 8 market influence & 0.23 & 0.15 & 0.27 & 0.30 & 0.18 & 0.26 \\
\hline 9 delivery status & 0.87 & 0.95 & 0.99 & 0.89 & 0.82 & 0.94 \\
\hline
\end{tabular}

\section{B. Dealing With Supplier Data Using Grey Correlation Analysi}

TABLE II COMPARING SERIES REFERENCE AND REFERENCE SEQUENCE VALUES

\begin{tabular}{|l|llllll|l|}
\hline $\begin{array}{l}\text { Evaluation } \\
\text { index }\end{array}$ & \multicolumn{3}{|l}{ Pending supplier } & & & & \\
\hline & 1 & 2 & 3 & 4 & 5 & 6 & \\
\hline & & & & & \\
Optimal & \\
\hline Indicator 1 & 0.00 & 0.44 & 1.00 & 0.56 & 0.25 & 0.75 & 1.00 \\
\hline Indicator 2 & 0.26 & 0.85 & 0.00 & 1.00 & 0.57 & 0.70 & 1.00 \\
\hline Indicator 3 & 0.61 & 0.00 & 0.46 & 0.68 & 0.39 & 1.00 & 1.00 \\
\hline Indicator 4 & 0.00 & 0.35 & 0.43 & 0.52 & 1.00 & 0.65 & 1.00 \\
\hline Indicator 5 & 0.46 & 0.67 & 0.12 & 1.00 & 0.46 & 0.00 & 1.00 \\
\hline Indicator 6 & 0.55 & 1.00 & 0.45 & 0.00 & 0.55 & 0.37 & 1.00 \\
\hline Indicator 7 & 0.67 & 0.20 & 1.00 & 0.33 & 0.00 & 0.17 & 1.00 \\
\hline Indicator 8 & 0.53 & 0.00 & 0.80 & 1.00 & 0.20 & 0.73 & 1.00 \\
\hline Indicator 9 & 0.29 & 0.76 & 1.00 & 0.41 & 0.00 & 0.71 & 1.00 \\
\hline
\end{tabular}

According to Table 3.2 above, the absolute difference between the reference sequence and each comparison sequence can be calculated. $\Delta_{i}(k)$ See Table 3 for details.

TABLE III CALCULATION RESULT

\begin{tabular}{|l|l|l|l|l|l|l|}
\hline $\begin{array}{l}\text { Evaluation } \\
\text { index }\end{array}$ & \multicolumn{4}{l}{ supplier } \\
\hline & 1 & 2 & 3 & 4 & 5 & 6 \\
\hline Indicator 1 & 1.00 & 0.56 & 0.00 & 0.44 & 0.75 & 0.25 \\
\hline Indicator 2 & 0.74 & 0.15 & 1.00 & 0.00 & 0.43 & 0.30 \\
\hline Indicator 3 & 0.39 & 1.00 & 0.54 & 0.32 & 0.61 & 0.00 \\
\hline Indicator 4 & 1.00 & 0.65 & 0.57 & 0.48 & 0.00 & 0.35 \\
\hline Indicator 5 & 0.54 & 0.3 & 0.88 & 0.00 & 0.54 & 1.00 \\
\hline Indicator 6 & 0.45 & 0.00 & 0.55 & 1.00 & 0.45 & 0.27 \\
\hline Indicator 7 & 0.33 & 0.0 & 0.00 & 0.67 & 1.00 & 0.83 \\
\hline Indicator 8 & 0.47 & 1.00 & 0.20 & 0.00 & 0.80 & 0.27 \\
\hline Indicator 9 & 0.71 & 0.24 & 0.00 & 0.59 & 1.00 & 0.29 \\
\hline
\end{tabular}

As can be seen from the data sheet in Table 3.3,

$\min i \min k \Delta_{i}(k)=0$, take $\xi=0.5$ Calculation $\xi(k)$ and $r_{i}$

The specific values are shown in Table 4.

TABLE IV CORRELATION COEFFICIENT AND RELEVANCE VALUE

\begin{tabular}{|l|l|l|l|l|l|l|}
\hline $\begin{array}{r}\text { Evaluation } \\
\text { index }\end{array}$ & \multicolumn{5}{|c|}{ supplier } \\
\hline & 1 & 2 & 3 & 4 & 5 & 6 \\
\hline Indicator 1 & 0.333 & 0.472 & 1.000 & 0.532 & 0.400 & 0.667 \\
\hline Indicator 2 & 0.403 & 0.769 & 0.333 & 1.000 & 0.538 & 0.625 \\
\hline Indicator 3 & 0.562 & 0.333 & 0.481 & 0.610 & 0.450 & 1.000 \\
\hline Indicator 4 & 0.333 & 0.435 & 0.467 & 0.510 & 1.000 & 0.588 \\
\hline Indicator 5 & 0.481 & 0.602 & 0.362 & 1.000 & 0.481 & 0.333 \\
\hline Indicator 6 & 0.526 & 1.000 & 0.476 & 0.333 & 0.526 & 0.649 \\
\hline Indicator 7 & 0.602 & 0.385 & 1.000 & 0.427 & 0.333 & 0.376 \\
\hline Indicator 8 & 0.515 & 0.333 & 0.714 & 1.000 & 0.385 & 0.649 \\
\hline Indicator 9 & 0.413 & 0.676 & 1.000 & 0.459 & 0.333 & 0.613 \\
\hline & 0.463 & 0.556 & 0.648 & 0.652 & 0.494 & 0.613 \\
\hline
\end{tabular}


From Table 4, it can be seen by sorting according to the degree of gray correlation. $r_{4}>r_{3}>r_{6}>r_{2}>r_{5}>r_{1}$ Since the supplier 4's relevance is the most relevant to the best supplier, that is, the supplier 4 is due to other suppliers, the decision makers of the company A can give priority to purchasing parts from the supplier 4 to achieve the overall optimum.

\section{CONCLUSION}

Taking A company as an example, this paper uses the gray correlation analysis method to combine the quantitative and qualitative methods for A's supplier selection decision-making problem for a large number of uncertain factors and mutual relations, so that Company A chooses the original supplier. Complex decision-making problems become clearer and simpler, and the calculation is convenient, and the subjective arbitrariness of the decision-makers can be ruled out to some extent, and the conclusions are more objective.

\section{ACKNOWLEDGMENT}

Dedicated my respect to an ordinary person, my tutor Hui Hongqi teacher. You are so rigorous in study, knowledgeable, broad-minded, and profound in thinking. You have created a good academic atmosphere for me to make my thesis more rigorous. At the same time, I would also like to thank the students who have completed the paper group together. Without your support and dedicated assistance, I can't solve these difficulties and doubts, and finally I can complete this article successfully.

\section{REFERENCES}

[1] Zhang Zhe. Research on supplier management improvement of $\mathbf{J}$ company [D]. Shandong University, 2019. (In Chinese)

[2] Zhao Yanfeng. How to choose suppliers for small household electrical appliances. Household appliances, 2017(8): 127. (In Chinese)

[3] Yu Yingying. Research on Supplier Management in Purchasing Process [J]. Building Materials and Decoration, 2018(43): 150-151. (In Chinese)

[4] Xx Jie, Zhang lanting. China's marina fishery industry structure based on grey relational analysis[j]. Ocean Development and Management,2018. (In Chinese)

[5] Zhao Jianfeng. Problems and Countermeasures of Supplier Management in Material Purchasing[J]. Petrochemical Technology,2018,25(10):294. (In Chinese)

[6] Du Dong. Pang Qinghua, "Modern Comprehensive Evaluation Method and Case Selection" [M]. Beijing. Tsinghua University Press, 2015. (In Chinese) 